\title{
Iterative Model Reconstruction (IMR) in MDCT Below 2 mSv for the Detection of Urinary Calculi: Diagnostic Accuracy and Image Quality in Comparison to Filtered Back-Projection and 4th Generation Iterative Reconstruction (iDose4)

\author{
Iterative Model Reconstruction (IMR) in der MDCT unter 2 mSv zur \\ Detektion einer Urolithiasis: Diagnostische Genauigkeit und \\ Bildqualität im Vergleich zur Filterrückprojektion und der
} iterativen Rekonstruktion der vierten Generation (iDose4)
}

Authors

Jakob Schmidt-Holtz' ${ }^{1}$, Azien Laqmani ${ }^{1}$, Sebastian Butscheidt ${ }^{1}$, Max Kurfürst ${ }^{1}$, Maxim Avanesov ${ }^{1}$, Cyrus Behzadi ${ }^{1}$, Clemens Spink', Simon Veldhoen ${ }^{2}$, Hans Dieter Nagel ${ }^{3}$, Gerhard Adam¹, Marc Regier ${ }^{1}$

Affiliations

1 Department for Diagnostic and interventionel Radiology, Endoscopy and Nuclear Medicine, University Hospital Hamburg Eppendorf, Hamburg, Germany

2 Department for Diagnostic and Interventionel Radiology, University Medical Center Würzburg, Germany

3 Research \& Technic for Radiology, Dr. HD Nagel, Buchholz, Germany

Key words

abdomen, image manipulation/reconstruction, CT, ureter, urinary tract, urolithiasis

received 22.03.2017

accepted 21.12.2017

Bibliography

DOI https://doi.org/10.1055/s-0044-100724

Published online: 2018

Fortschr Röntgenstr 2018; 190: 630-636

(c) Georg Thieme Verlag KG, Stuttgart · New York

ISSN 1438-9029

Correspondence

Jakob Schmidt-Holtz

Department of Diagnostic and Interventional Radiology,

University Medical Center Hamburg-Eppendorf,

Harvestehuder Weg 55, 20149 Hamburg, Germany

Tel.: ++49/0 17/24065549

jak.schmidt-holtz@uke.de

\section{ZUSAMMENFASSUNG}

Ziel Das Ziel dieser Studie war es, die Auswirkungen der iterativen Modellrekonstruktion (IMR) auf die Sicherheit des Radiologen bei der Steindetektion und auf die Bildqualität im Vergleich zu gefilterten Rückprojektionen (FBP) und iDose
Level 4 (iDose4) im Stein-MDCT mit Strahlendosen unter $2 \mathrm{mSv}$ zu beurteilen.

Materialien und Methoden Für 32 aufeinanderfolgende Patienten mit Verdacht auf ein Harnleiterkonkrement wurden die Rohdaten der nativen Scans (256 Slice MDCT, 120 kV, 40 Referenz mAs, mittleres CTDIvol: 2,7 $\pm 0,8 \mathrm{mGy}$, mittleres DLP: $126 \pm 38 \mathrm{mGy} \times \mathrm{cm})$ unter Verwendung einer Prototypversion von IMR (Level $1-3$ ), iDose4 (Level 4) und FBP mit einer Schichtdicke von $3 \mathrm{~mm}$ rekonstruiert. Die Bildanalyse wurde jeweils unabhängig von zwei geblindeten Radiologen durchgeführt. Die diagnostische Sicherheit des Radiologen bei der Steindetektion erfolgte auf der Grundlage einer 5Punkte-Skala (1 - sicherer Ausschluss, 5 - Konkrement definitiv vorhanden) wie auch für die Auswertung der Bildqualität in Bezug auf die Darstellung von anatomischen Details (1 - mangelhaft; 5 - Ausgezeichnet). Ein klinischer Referenzstandard für die Steindetektion wurde nicht erhoben. Die statistische Auswertung beinhaltet die weighted kappa-analysis und den Wilcoxon-Test.

Ergebnisse 17 Nierenbecken- und Uretersteine wurden gefunden. 11 weitere Konkremente wurden im Harnblasenostium oder der Harnblase selber lokalisiert. Bei der Anwendung von IMR wurde mit jeder Iterationsstufe eine deutliche Verbesserung der Bildqualität beobachtet (Mittelwert für FBP, 2,0, iDose4, 2,9, IMR L1, 4,2, IMR L2, 4,0, IMR L3, 3,9, alle $p<0,001$ ). Mit den höheren IMR-Stufen L2 und L3 wurde ein gewisses Maß an sogenannter „blotchiness“ (Unschärfe) anatomischer Konturen beobachtet. Die Sicherheit des Radiologen wurde so unabhängig vom IMR-Level signifikant verbessert (sichere Steindetektion FBP, 69\%; iDose4, $81 \%$; IMR L1 bis L3, $95 \%$, alle $p>0,001$ ). Mit zunehmenden IMR-Werten wurde die Reduktion von Streifenartefakten durch eine Abnahme des Bildrauschens quantifiziert. Ein Verlust anatomischen Informationen wurde nicht beobachtet. Die Sensitivität der Steindetektion waren äquivalent für alle MDCTs, die 
mit FBP, iDose4 oder IMR rekonstruiert wurden. Es wurde eine mittlere effektive Dosis von 1,9 $\pm 0,6 \mathrm{mSv}$ berechnet.

Schlussfolgerung Eine Urolithiasis kann zuverlässig durch MDCT bei deutlich reduzierten Dosiseinstellungen unter 2 mSv detektiert werden. Im Vergleich zu FBP und iDose4 kann eine signifikante Erhöhung der durchschnittlichen Bildqualität, eine Verringerung des Bildrauschens und eine Verbesserung der subjektiven diagnostischen Sicherheit des Radiologen bei der Konkrementdetektion mit Hilfe von IMR erreicht werden. Dies deutet darauf hin, dass mit IMR weiterreichende Dosisreduktionen möglich sein könnten.

\author{
Kernaussagen \\ - Urogenitaltrakt \\ - Urolithiasis \\ - Iterative Reconstruction
}

\section{ABSTRACT}

Purpose The purpose of the study was to assess the impact of iterative model reconstruction (IMR) on reader confidence with respect to stone detection and image quality in comparison to filtered back-projection (FBP) and iDose level 4 (iDose4) in abdominal MDCT with radiation doses below $2 \mathrm{mSv}$.

Materials and Methods For 32 consecutive patients with suspected ureteral stone disease, the raw data of unenhanced 256 slice MDCT (120 kV, 40 reference mAs, mean CTDIvol: 2.7 $\pm 0.8 \mathrm{mGy}$, mean DLP: $126 \pm 38 \mathrm{mGy} \times \mathrm{cm}$ ) were reconstructed using a prototype version of IMR (levels $1-3$ ), iDose4 (level 4) and FBP at a $3 \mathrm{~mm}$ slice thickness. Image analysis was independently performed by two radiologists in a blinded fashion. The reader confidence level with respect to stone detection was recorded based on a 5-point scale (1 - certain exclusion; 5 - concrement definitely present) as well as for the evaluation of image quality regarding the depiction of anatomical details (1 - poor; 5 - excellent). A clinical reference standard for stone detection was not established. Statistical evaluation included weighted kappa analysis and Wilcoxon test.
Results 17 pelvic and ureteral stones were found. 11 further concrements were located within the ostium of the urinary bladder or the bladder itself. Applying IMR, a distinct improvement in image quality was observed at every level (mean value for FBP, 2.0; iDose4, 2.9; IMR L1, 4.2; IMR L2, 4.0; IMR L3, 3.9; all p<0.001). Applying the higher IMR levels L2 and L3, a certain level of so-called "blotchiness" of anatomical contours was observed. Reader confidence was significantly improved and was independent of IMR level (certain stone detection FBP, 69\%; iDose4, 81\%; IMR L1 to L3, $95 \%$; all p >0.001). With increasing IMR levels, the reduction in streak artifacts was quantified by a decrease in image noise. A loss of anatomical information was not observed. The sensitivity rates for stone detection were equivalent for all MDCTs reconstructed with FBP, iDose4 and IMR. A mean effective dose of 1.9 $\pm 0.6 \mathrm{mSv}$ was calculated.

Conclusion In comparison to FBP and iDose4, a significant increase in mean image quality, reduction in image noise and improvement in subjective reader confidence can be achieved by applying IMR even at significantly reduced dose settings below $2 \mathrm{mSv}$. Results indicate that a further dose reduction might be possible with IMR.

\section{Key Points}

- Urinary tract

- urolithiasis

- iterative reconstruction

\section{Citation Format}

- Schmidt-Holtz J, Laqmani A, Butscheidt S et al. Iterative Model Reconstruction (IMR) in MDCT Below 2mSv for the Detection of Urinary Calculi: Diagnostic Accuracy and Image Quality in Comparison to Filtered Back-Projection and 4th Generation Iterative Reconstruction (iDose4). Fortschr Röntgenstr 2018; 190: 630-636

\section{Introduction}

Multidetector computed tomography (MDCT) has already proven its high diagnostic value by achieving a high sensitivity (98\%) and specificity (96\%) in the detection of urinary stone disease [1]. Over the last decade, the number of MDCT scans performed for the detection of urinary stone disease has continuously increased [2].

With a lifetime-estimated recurrence rate of approximately over $50 \%$ [3], patients suffering from urolithiasis are often repeatedly referred for cross-sectional imaging. The portion of young patients affected is above-average [4].

In combination with the growing accessibility and usage of MDCT in these cases, the scans have evolved to become an increasing part of population radiation exposure.

As a result, development of low-dose protocols was needed. After broad implementation, these have proven to be efficient and further accepted as a standard procedure for the diagnosis of urolithiasis [5-7]. Early ethical concerns [8,9] have been invalidated [10].

However, with this development growing image noise proved to be the trade-off for lowering radiation dose levels. Iterative reconstruction (IR) tools have been shown to be successful in compensating for this loss in image quality at the existing dose reduction levels in the past [11 - 13]. With ongoing improvement of IR tools and its ability to decrease even higher image noise ratios, the radiation dose reduction potential changes and needs to be re-evaluated each time.

Most recently, a new generation of IR tools called Iterative Model Reconstruction (IMR ${ }^{\circledR}$; Philips Healthcare, Best, the Netherlands) was introduced. With the underlying target being to once again lower radiation dose exposure "as low as reasonably achievable" (ALARA), the new potential capability of IMR to allow for further lowering has to be evaluated. 
Thus, the purpose of this study is to assess the impact of IMR on reader confidence with respect to stone detection and on image quality in comparison to FBP and iDose4 in abdominal MDCT with radiation doses below $2 \mathrm{mSv}$.

\section{Materials and Methods}

\section{Patient collective}

In this retrospective study the data from 32 consecutive patients (21 men; mean age: 53.5 years; range: 20 - 82 years) with suspected urinary stone disease were analyzed.

The study was reviewed and approved by the local ethics committee. Due to the retrospective nature of the study protocol, the ethical review board waived the need for written informed consent.

\section{MDCT image acquisition}

MDCT examinations were performed using a 256-slice MDCT scanner (Brilliance iCT, Philips Healthcare, Best, The Netherlands). All patients underwent non-contrast MDCT of the upper urinary tract performed in craniocaudal direction from the top of the kidneys to the bottom of the urinary bladder. As only a prototype version of IMR was available in our study, which was neither FDAnor CE-cleared, regular diagnosis based on images reconstructed with IMR was not allowed. Hence, the dose settings that were appropriate for iDose, which was used for regular diagnosis, had to be applied, using the following parameters: tube voltage of $120 \mathrm{KV}$; reference tube current time product of $40 \mathrm{mAs}$, corresponding to a CTDlvol of $2.7 \mathrm{mGy}$ for a standard-sized patient; gantry rotation time of $0.4 \mathrm{~s}$; pitch of 0.922 ; collimation of $64 \times 1.25 \mathrm{~mm}$. Automatic exposure control system (ACS) in combination with z-axis dose modulation (Z-DOM) was activated.

\section{MDCT image reconstruction:}

The raw data of all MDCTs were reconstructed with FBP, iDose ${ }^{4}$ (level 4) and three different IMR levels (IMR level 1 (IMR L1), level 2 (IMR L2) and level 3 (IMR L3)) allowing for an intraindividual comparison between all reconstruction methods.

IMR reconstruction was performed with the "Body Routine" setting. The different levels of IMR refer to the degree of noise reduction provided by the IMR software. In the case of FBP and iDose, the standard body kernel (B) was applied. A slice thickness of $3 \mathrm{~mm}$ with $50 \%$ overlap was used for all data sets. The recommended fixed setting "BodyRoutine" was used for IMR.

\section{Subjective image evaluation}

Multiplanar reconstructions were created for every examination. A commercially available PACS system (Centricity PACS-IW, GE Healthcare, Chicago, Illinois, United States) was used for image interpretation. Two radiologists with 5 and 10 years of abdominal MDCT experience independently evaluated all data sets in a blinded fashion.
All reconstructions were randomized and six separate review sessions were performed in order to achieve a maximum level of blinding.

The subjective image quality was rated based on a 5-point Likert scale defined as follows:

1. poor image quality, major noise, with poorly defined anatomic details.

2. reduced image quality, substantial noise, with limitations in anatomic details.

3. acceptable image quality, moderate noise.

4. good image quality, minor noise, with clear anatomic details.

5. excellent image quality, no noise, with distinct anatomic details.

Ratings were separately performed for the renal pelvis, the urinary bladder, and the proximal, middle and distal third of the ureteral course. The rating of anatomical structures was mainly influenced by the ability to clearly outline the displayed anatomical borders with particular regard to the urinary and renal tract.

For the determination of image appearance and the known blurring effect of IR techniques, the 5-point Likert scale targeted the "blotchiness" of the entire MDCT data set influencing the detailed depiction of anatomical details only:

1. major blotchy appearance.

2. increased blotchy appearance.

3. moderate blotchy appearance.

4. minor blotchy appearance.

5. no blotchy appearance.

Reader confidence with respect to diagnosing urolithiasis was graded dividing the data into the sections identical to those performed for the analysis of the subjective image quality (renal pelvis, proximal, middle and distal ureteral third and the urinary bladder, respectively). Ratings were performed for both the left and the right side separately, applying the following definition of calculus score:

1. definitely no calculus

2. probably no calculus

3. indeterminate

4. probably calculus

5. definitely calculus

Finally, consensus readout was performed and the reference standard was defined. To determine the diagnostic value, definite stone detection or exclusion groups were determined. A relation to possible findings was set and a 'confidence' index was generated, which is defined as

$$
\text { confidence index }=\frac{\text { number of cases with calculus score } 1 \text { or } 5}{\text { total number of cases }}
$$

Thus, reader confidence with respect to diagnosis was evaluated. A subsequent correlation of the radiologist's diagnosis and clinical findings of urolithiasis or the lack thereof was not carried out. Thus, a corresponding reference standard was not established. 


\section{Objective image evaluation}

\section{Radiation dose and noise levels}

For every MDCT scan a dose report was generated. All relevant dose parameters including CT dose index volume $\left(\mathrm{CTDI}_{\mathrm{vol}}\right)$, doselength product (DLP) and tube voltage (KV) were documented.

For the quantitative analysis the Hounsfield Units (HU) and the standard deviations (SD) were determined by placing circular regions of interest at the following locations: the subcutaneous fat at the dorsolateral back; the right subcutaneous gluteal fat; the aortic lumen; the internal obturator muscle and the urinary bladder. These measurements were performed on three adjacent slices and mean values were obtained.

\section{Statistical analysis}

Continuous variables were expressed as mean \pm SD. Categorical variables are presented as mean $+95 \%$ confidence interval. Intergroup comparisons between $\geq 3$ related groups were assessed applying the Friedman-test. Post-hoc analysis between 2 related groups was performed using the paired Student's t-test for normally distributed data and the Wilcoxon signed-rank test for skewed data samples. Interobserver agreement between the two reviewers was assessed by weighted kappa. Statistical significance was defined for 2 -tailed $p$-values of less than 0.05 . Data collection and statistical calculations were performed using SPSS Statistics 22 software (IBM Inc. SPSS Statistics, Chicago, IL).

\section{Results}

\section{Subjective image quality}

The subjective image quality results for each part of the urinary tract are displayed in $\mathbf{F i g . 1}$. First, a mean score for the image quality of the upper urinary tract was generated for all segments. The scores substantially increased from FBP to iDose ${ }^{4}$ as well as from iDose ${ }^{4}$ to IMR. FBP scored an average of 2.0 points on the Likert scale. iDose ${ }^{4}$ accomplished an average score of 2.9. IMR level 1 was rated to perform with a substantial increase in the subjective image quality (4.2) and a decrease of image noise. With further noise reduction by the IMR software at the higher levels 2 and 3 , the mean score for image quality slightly decreased to an average of 4.0 and 3.9 , respectively.

\section{Objective image quality}

The CT numbers remained constant for each anatomical structure. No substantial differences between iteration tools or levels were found. No pattern of deviation could be related. The observed extent of variation ranged from $0.5 \%$ to $2.0 \%$. The mean SD determined for all anatomical landmarks showed a considerable decrease when applying iDose ${ }^{4}$ and IMR in comparison to FBP. Using iDose ${ }^{4}$ with level 4 , image noise was reduced by $45 \%$ on average. IMR L1 allowed for an even greater reduction of $70 \%$. With IMR L3 the highest noise reduction of $79 \%$ was achieved. The constancy of the mean CT numbers as well as the reduction in mean SD were calculated for each anatomical structure as shown in $>$ Fig. 2.

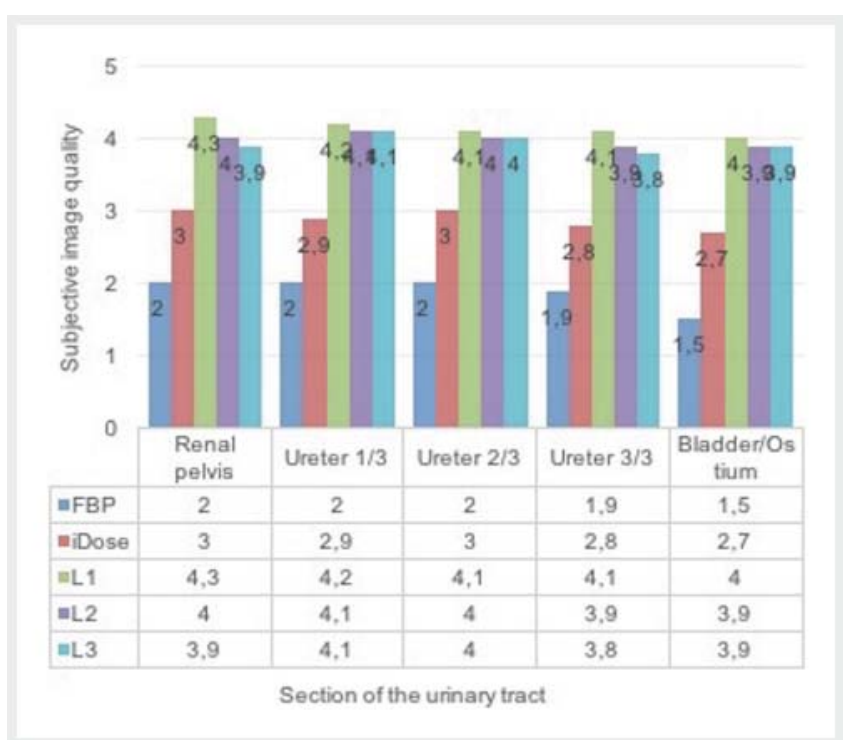

- Fig. 1 Impact of FBP, iDose4 and IMR levels 1 - 3 on mean subjective image quality for each section of the urinary tract.

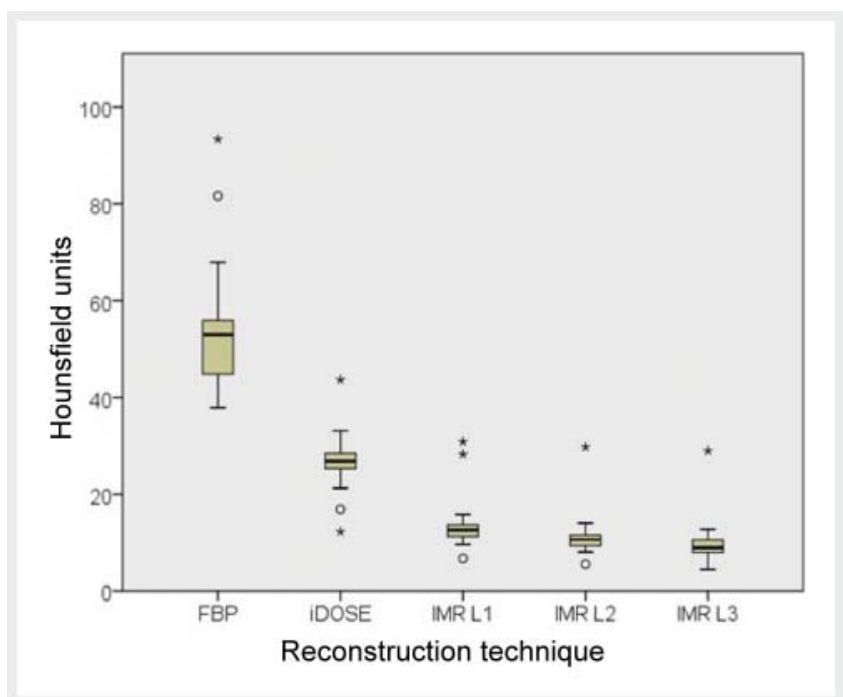

- Fig. 2 Continuous decrease in noise levels from FBP to iDose4 and ongoing from IMR levels 1 to 3 in the urinary bladder as an example. No substantial alteration in CT numbers (HU mean) can be observed.

\section{Reader confidence with respect to stone detection}

The results show an increase in reader confidence with respect to definite stone detection and exclusion from FBP to iDose ${ }^{4}$ and to IMR. FBP achieved a confidence index of $66 \%$, iDose $\mathrm{D}^{4}$ of $81 \%$ and IMR of $96 \%$ independent of the level ( $\triangleright$ Fig. 3). Both radiologists reported a high influence of the extent of distinction of anatomical structures on their confidence regarding stone detection. This particularly affected evaluation in the area of the lower ureter and bladder.

A drop of only $2 \%$ with IMR level 1 and $3 \%$ with levels 2 and 3 from the upper to the lower urinary tract was observed. Subse- 


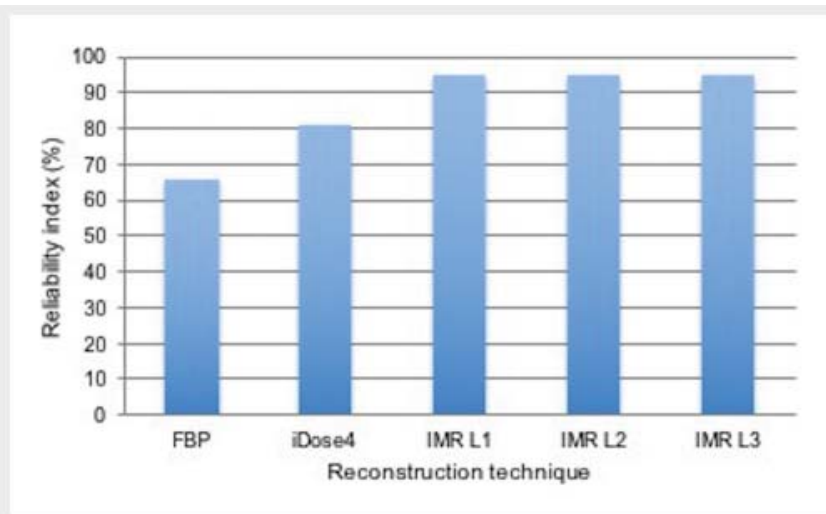

- Fig. 3 Rising reader confidence in stone detection from FBP to iDose4 and to IMR levels $1-3$ (L1 - 3).

quently, a nearly consistent high level of reliability with IMR level 1 (96\%) and level 2 (97\%) was shown. With FBP and iDose ${ }^{4}$, however, a drop of $26 \%$ (FBP) and $16 \%\left(\right.$ iDose $^{4}$ ) was shown.

\section{Image appearance and noise}

No blotchy appearance was found on the images reconstructed using FBP (mean value of 5). Alterations in the image appearance were noted only with the introduction of iDose ${ }^{4}$ or IMR. In iDose ${ }^{4}$ the blotchiness was assessed to be between minor and no blotchy appearance (mean value of 4.6). With further influence of the IMR reconstruction technique, increasing blotchiness was observed (mean values of 3.7 (IMR L1), 3.2 (IMR L2) and 2.8 (IMR L3)), resulting in a moderate blotchy image appearance.

\section{Radiation dose}

The mean effective tube current time product was $41 \pm 12 \mathrm{mAs}$ (range 19-80 mAs) with a fixed tube voltage of $120 \mathrm{KV}$. The mean $\mathrm{CTDI}_{\text {vol }}$ was $2.7 \pm 0.8 \mathrm{mGy}$ (range $1.29-5.44 \mathrm{mGy}$ ). On average, the DLP amounted to $126 \pm 38 \mathrm{mSv} \times \mathrm{cm}$ (range from $49-253 \mathrm{mSv} \times \mathrm{cm}$ ). By applying the conversion factor of $\mathrm{k}=0.015 \mathrm{mSv} / \mathrm{mGy} \times \mathrm{cm}$ from AAPM report 96 , this resulted in an overall mean effective dose of $1.9 \pm 0.6 \mathrm{mSv}$.

\section{Discussion:}

MDCT has been shown to be highly reliable in the diagnosis of urinary stone disease [14]. However, the challenge to diminish radiation dose exposure remains. With the initial introduction of IR techniques, a continuous reduction of MDCT dose settings with a simultaneous positive influence on image quality was achieved in the past.

Several studies have evaluated the impact of IR on image quality parameters as well as on the reader's diagnostic confidence with regard to pinpointing pathological findings. Not only the detection of urolithiasis but also various other types of CT examinations and findings were investigated [15-17]. With the very recent introduction of the next generation IR tool IMR, this study

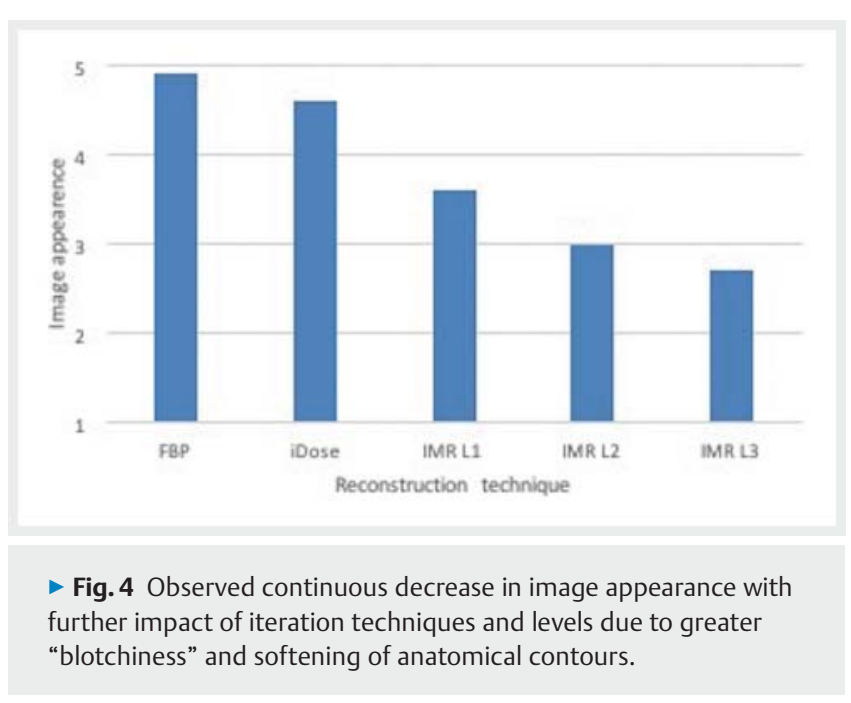

aimed to evaluate the changes of these effects in comparison to its predecessors FBP and iDose ${ }^{4}$.

Our results show that IMR reduces image noise and increases reader confidence with respect to stone detection to a large extent. This is reflected in substantially reduced noise levels (reduction of $70 \%$ to $80 \%$ in comparison to FBP and of $50 \%$ to $60 \%$ in comparison to iDose ${ }^{4}$ (level 4)) and improved reader confidence with regard to stone detection (from $66 \%$ with FBP to $81 \%$ with iDose $^{4}$ and $96 \%$ with each IMR level ( $\triangleright$ Fig. 3 )). Thus, an increase of up to $30 \%$ from FBP to IMR and of $15 \%$ from iDose 4 to IMR was observed, which represents a significant improvement.

However, with growing influence of the IMR algorithm in higher IMR levels, especially IMR level 3, a noticeable altering of image appearance can be observed. This alteration, in other studies already described as "blotchiness" or a "waxy" appearance, refers to blurring with a loss of sharpness of anatomical contours $[14,18]$. This visual phenomenon accounts for the reduction of subjective image quality as well as the image appearance score despite an ongoing noise reduction from IMR level 1 to level 3

( Fig. 4).

The decrease in image appearance from IMR L1 to L3, however, had no negative impact on reader confidence regarding stone detection. This is due to the fact that the high density of urinary calculi allows easy identification in non-enhanced abdominal MDCT independent of the reconstruction technique ( $\mathbf{F i g . 5}$ ). Especially in IMR L3, discrete alterations of anatomical details had no significant impact on reader confidence. Still it has to be taken into account that no clinical reference standard was defined. Instead, the problem reported by both readers was not the identification but in some cases the reliable assignment of possible calculi to part of the urinary tract. This problem was mainly caused by higher noise levels arising partly from lower noise reduction potential, especially by FBP, and partly from anatomical regions often related to higher noise levels and artifacts. Referring to the urinary tract, these regions are the middle and lower third of the ureter as well as the urinary bladder and its ostia ( $>$ Fig. 1, 5). In many cases this problem is essential for differentiation between urolithiasis and nonspecific calcifications such as phleboliths or calcified lymph nodes. 


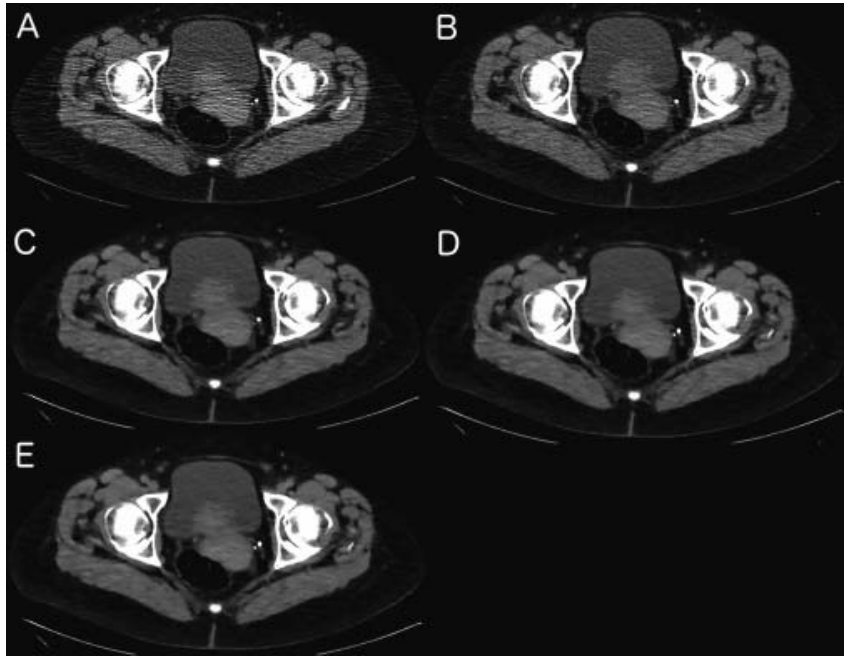

- Fig. 5 Urinary stone detection in the lower left ureter. A: FBP; B: iDose4; C: IMR L1; IMR L2; IMR L3. The example demonstrates the ongoing decrease in image appearance with higher iteration levels. Due to increasing delineation of the ureter, the assignability of the concrement improves.

In this study reader confidence regarding stone detection varied greatly from the upper urinary tract to the lower. This change in reader confidence, however, directly depends on the IR tool being used. With FBP the confidence index dropped by $23 \%$ (from $69 \%$ to $43 \%$ ) and with iDose 4 by $16 \%$ (from $84 \%$ to $68 \%$ ) from the upper to the lower urinary tract, whereas a drop of only a few percent was observed with IMR (L1 from $96 \%$ to $94 \%$, L2 and L3 from $97 \%$ to $94 \%$ ). This leads to the conclusion that even though higher IMR levels alter image appearance and even very fine anatomical structures can potentially be lost [19], the diagnostic value for this specific task substantially improves. Nevertheless, the discussion of missing a possible differential diagnosis with altering image appearance as stated by Veldhoen et al. [14] remains.

However, CT examinations for urolithiasis especially concern young patients who often undergo multiple CT scans over the years [14]. The obligation to consider radiation dose-related cancer risks remains unchanged $[4,20,21]$. Based on our results, as well as similar results [15], the newly introduced radiation dose reduction potential offered by IMR has to be discussed.

Our study achieved an average effective dose of $1.9 \mathrm{mSv}$ without altering the already implemented standard dose settings. In consideration of the significant improvements in reader confidence, a further dose reduction should be possible with IMR. This was shown by Park et al. as well as other studies [22-25], which achieved average effective dose levels as low as $0.68 \mathrm{mSv}$. Future studies need to evaluate the full dose reduction potential, taking the loss of a possible differential diagnosis and the alteration of image appearance into account. The trade-off needs to be evaluated and optimal dose settings have to be identified.

This study had the following limitations:

As already mentioned, the prototype version of IMR used in this study had no FDA or CE clearance. To ensure regular diagnosis without IMR, the impact of reductions below the level that is appropriate with iDose could not be investigated.

Based on the fact that a clinical correlation of the radiologist's interpretations did not take place, the possible radiological diagnoses of urolithiasis could not be confirmed or disproved. Thus, a clinical reference standard is not defined.

Even though the radiologists were blinded, an ideal blinding could not be assured in all cases due to the visible differences between each iterative reconstruction technique (FBP, iDose ${ }^{4}$ and IMR), such as noise levels and sharpness of anatomical structures.

A further limitation was that possible differential diagnoses were not investigated. IMR proved to have a positive effect on reader confidence regarding the diagnosis or exclusion of urolithiasis. On the other hand, the loss of a possible differential diagnosis due to an alteration in image appearance by the IMR algorithm, especially in IMR L3, remains uncertain.

Furthermore, the size of possible stones and a final confirmation of determined stones were not established in this study.

In conclusion, IMR substantially exceeds the capability of its predecessors iDose ${ }^{4}$ and $\mathrm{FBP}$ to improve image noise levels as well as subjective image quality for non-enhanced low-dose MDCT of the urinary tract. Thus, on the basis of missing clinical correlation, considerably better subjective reader confidence was achieved.

The results of the presented study allude to a further potential to reduce radiation dose exceeding the dose settings applied. However, the extent of this potential needs to be clarified in future studies.

\section{Conflict of Interest}

The authors declare that they have no conflict of interest.

\section{References}

[1] Dhar M, Denstedt JD. Imaging in diagnosis, treatment, and follow up of stone patients undergoing unenhanced in patients. Adv Chronic Kidney Dis 2009; 16: 39-47

[2] Sung MK, Sarabjeet S et al. Current Status of Low Dose Multi-Detector CT in the Urinary Tract. World Journal of Radiology 2011; 3: 256-265. doi: 10.4329/wjr.v3.i11.256

[3] Andrabi Y, Patino M et al. Advances in CT Imaging for Urolithiasis. Indian Journal of Urology: IJU. Journal of the Urological Society of India 2015; 31: $185-193$

[4] Brenner DJ, Hall EJ. Computed tomography-an increasing source of radiation exposure. Engl J Med 2007; 357: 2277-84

[5] Pak CY. Kidney stones. Lancet 1998; 351: 1797-1801

[6] Catalano O, Nunziata A, Altei F et al. Suspected ureteral colic: primary helical CT versus selective helical $C T$ after unenhanced radiography and sonography. Am J Roentgenol 2002; 178: 379-387

[7] Karul M, Heuer R, Regier M. Multidetector computed tomography of urolithiasis: technique and results. Rofo 2013; 185: 121-127

[8] Tamm E, Silverman P, Shuman W. Evaluation of the Patient with Flank Pain and Possible Ureteral Calculus. Radiology 2003; 228: 319-329

[9] Katz SI, Saluja S, Brink J et al. Radiation dose associated with unenhanced CT for suspected renal colic: impact of repetitive studies. Am J Roentgenol 2006; 186 (4): $1120-1124$ 
[10] Niemann T, Van Straten M, Resinger C et al. Detection of urolithiasis using low-dose CT - A noise simulation study. Eur J Radiol 2011; 80 (2): $213-218$

[11] Thibault JB, Sauer KD, Bouman CA et al. A three-dimensional statistical approach to improved image quality for multislice helical CT. Med Phys 2007; 34: 4526-4544

[12] Hara AK, Paden RG, Silva AC et al. Iterative reconstruction technique for reducing body radiation dose at CT: feasibility study. Am J Roentgenol 2009; 193: $764-771$

[13] Noël PB, Fingerle AA, Renger B et al. Initial performance characterization of a clinical noise-suppressing reconstruction algorithm for MDCT. Am J Roentgenol 2011; 197: 1404-1409

[14] Veldhoen S, Laqmani A, Derlin T et al. 256-MDCT for evaluation of urolithiasis: iterative reconstruction allows for a significant reduction of the applied radiation dose while maintaining high subjective and objective image quality. J Med Imaging Radiat Oncol 2014; 58 (3): 283 - 290

[15] Park SB, Kim YS, Lee JB et al. Knowledge-based iterative model reconstruction (IMR) algorithm in ultralow-dose CT for evaluation of urolithiasis: evaluation of radiation dose reduction, image quality, and diagnostic performance. Abdom Imaging 2015; 40: 3137 - 3146. doi: 10.1007/s00261-015-0504-y

[16] Neisius A, Wang AJ, Wang C et al. Radiation exposure in urology: a genitourinary catalogue for diagnostic imaging. J Urol 2013; 190 (6): 2117 2123

[17] Niemann T, Kollmann T, Bongartz G. Diagnostic performance of lowdose CT for the detection of urolithiasis: a meta-analysis. Am J Roentgenol 2008; 191 (2): $396-401$
[18] Laqmani A, Buhk JH, Henes FO et al. Impact of a 4th generation iterative reconstruction technique on image quality in low-dose computed tomography of the chest in immunocompromised patients. Rofo 2013; 185 (8): $749-757$

[19] Laqmani A, Avanesov M, Butscheidt S et al. Comparison of image quality and visibility of normal and abnormal findings at submillisievert chest CT using filtered back projection, iterative model reconstruction (IMR) and iDose4 ${ }^{\mathrm{TM}}$. Eur J Radiol 2016; 85 (11): 1971 - 1979

[20] Amis ES Jr., Butler PF, Applegate KE et al. American College of Radiology white paper on radiation dose in medicine. J Am Coll Radiol 2007; 4: $272-284$

[21] Mettler FA Jr., Bhargavan M, Faulkner K et al. Radiologic and nuclear medicine studies in the United States and worldwide: frequency, radiation dose, and comparison with other radiation sources. Radiology 2009; 253: 520 - 531. doi: 10.1148/radiol.2532082010

[22] Pickhardt P], Lubner MG, Kim DH et al. Abdominal CT with model-based iterative reconstrction (MBIR): initial results of a prospective trial comparing ultralow-dose with standard-dose imaging. Am J Roentgenol Am j Roentgenol 2012; 199: 1266-1274

[23] Vardhanabhuti V, llyas S, Gutteridge C et al. Comparison of image quality between filtered back-projection and the adaptive statistical and novel model-based iterative reconstruction techniques in abdominal CT for renal calculi. Insights Imaging 2013: 661 - 669

[24] Botsikas D, Stefanelli S, Boudabbous S et al. Model-based iterative reconstruction versus adaptive statistical iterative reconstruction in lowdose abdominal CT for urolithiasis. Am J Roentgenol 2014; 203: 336 340

[25] Pooler BD, Kubner MG, Kim DH et al. Prospective trial of the detection of urolithiasis on ultralow dose (sub $\mathrm{mSv}$ ) noncontrast computerized tomography: direct comparison against routine low dose reference standard. J Urol 2014; 192: 1433 - 1439 